\title{
Disruptive Technologies in the Operation of Insurance Industry
}

\author{
Vladimir NJEGOMIR, Jelena DEMKO-RIHTER*, Tamara BOJANIĆ
}

\begin{abstract}
The aim of this paper is to present and discuss the opportunities and risks related to implementation of new digital disruptive technologies in the operation of insurance companies. We compare theoretical knowledge and empirical evidence of six alternative approaches of digitalization implementation in insurance companies. We review trends and analyse the application of information technologies in risk management, in sales and distribution, Insurtech, big data and predictive analytics, Internet of things (loT), telematics devices and Blockchain technology in insurance. Regardless of the threats related to digitalization processes and increasing number of "attackers" in the insurance sector, insurance companies are slowly and gradually embracing new technologies, adapting their strategies, organizational structures, risk management, employees and culture in order to add value to their companies and to the customers.
\end{abstract}

Keywords: digitalization; innovation; insurance; risk

\section{INTRODUCTION}

The entire economic and social development so far has been characterized by a certain type of technology. Modern technological changes, especially information and communication, but also biotechnology and nanotechnology, are gradually transforming the economy and the society, creating new ways of working and new types of jobs. They provide solutions to the key sociological challenges such as health care, the environment, security, mobility and employment. The purpose of insurance is to undertake risks and support economic growth, but the insurance industry also has a significant positive impact on the entrepreneurship and innovation, since it provides not only protection against risks but also financial resources through investments in the financial market. However, changes in insurance occur very slowly and the insurance sector is considered to be conservative.

The digital era brings a radical shift in the nature and scope of risks to society. Schmidt [1] argues that digitalization is widening the role of insurers allowing them to evolve from mere risk protectors towards risk predictors and preventers. Instead of being primarily concerned with loss indemnification, insurers are becoming a broader advisory service provider, helping insureds make decisions on how to prevent, mitigate, and manage risks. According to Eling and Lehmann [2] digitalization is the integration of the analogue and digital world with new technologies that enhance customer interaction, data availability and business processes.

Newman [3] points out that when it comes to digital transformation risk is part of every decision - every chosen app, every cloud that inhabits important data and every experience created for customers. Digital transformation needs risk management because risk management provides the structure, we need to understand the points at which our digital transformation projects can go wrong. But risk management does not make a project succeed. Disruptive technology refers to a technology whose application affects the way a market or industry operates. The business models that adapt to new technologies generate new markets and values which could lead to the disruption of wellestablished companies [4].
The digitalization of insurance impacts issues of strategy, risk, market and organizational structure, workforce, and culture issues [5].

Deloitte [6] has identified 10 risk areas in any digital ecosystem - Strategic, Technology, Operations, Third Party, Regulatory, Forensics, Cyber, Resilience, Data Leakage and Privacy. Based on the applicable risk areas for the digital initiatives, different control measures need to be designed as per leading standards and industry practices.

In the case of information technology, the biggest risk to date is cyber risk. The most well-known examples of cyber risk exposure, both due to financial impact and media, are the thefts of confidential identity information of individuals. According to estimates by the Federal Trade Commission, these thefts negatively affect about 10 million people annually and cause unwanted costs of about $\$ 50$ billion. Also, a lot of cases indicate that the risks associated with the use of information technology can threaten many other types of insurance coverage [7]. For example, an attack by hackers on the computerized control system of an irrigation plant in Australia led to flooding of parks and rivers, causing huge water pollution [8]. Threatening public services by hacking attacks can have unprecedented consequences, which can produce significant damage to various types of insurance coverage. Therefore, insurance companies must also consider these scenarios when managing risks and determining insurance premiums, while encouraging the implementation of preventive measures.

Implementation of new digital technologies in insurance should result in easier access to insurance services, new products and new partnerships, better underwriting and pricing, lower operating costs and higher profits.

The main research hypothesis is:

Disruptive technologies enable creation of added value in the operation of insurance companies.

The paper is structured as follows: after the introduction, the methodology approach has been explained. The next parts of the paper are results of the research, followed by main conclusions and relevant literature. 


\section{RESEARCH METHODOLOGY}

Our research encompasses the analysis of the opportunities and threats of digitalization in insurance. The primary focus is on various means of application of digitalization in insurance and their specifics.

We compare six alternative approaches of digitalization implementation in insurance companies, by comparing theoretical knowledge and empirical evidence. We review trends, and analyse the application of information technologies in risk management, application of information technologies in sales and distribution, Insurtech, big data and predictive analytics, Internet of things (IoT), telematics devices and Blockchain technology in insurance.

The basic intent is to change the traditional view of insurance industry as a conservative industry for which there are no innovations that are in accordance with the characteristics of insurance business. The fact is that the insurance industry is strictly regulated and must be conservative in its business for the sake of insureds, but that does not mean that in the era of digitalization, the insurance industry should be exempted.

We analyse the most important aspects of digitalization and their applicability to the insurance industry. We use historical analysis of trends, comparative analysis of the application of digitalization in insurance and for comparison empirical examples of best practice, and statistical analysis of trends that we explore for each method of digitalization, especially the most important trends of insurtech and predictive analytics. We review current achievements in order to determine what has already been done, what needs to be done, and what can possibly be done to improve the business of insurance companies.

The data was gathered from various trustful sources. We use the sources from various leading scientists in the field, including a Nobel Prize nominee. We base our conclusions on data from Google trends, Fintech Global, Accenture, Boston Consulting Group (BCG), Terra Seismic, various insurance companies, and other sources.

\section{RESULTS}

\subsection{Use of Information Technologies in Risk Management}

Regulation, product complexity, and insurers' large balance sheet sums have kept digital attackers from insurers' gates [9]. The development of information technology forces insurance companies to become innovative in order to survive, although they are conservative about developing and adopting innovations. Insurers should aim to adopt a faster, analytics-driven approach to claims handling and fully automate the claims handling processes for clear and simple cases [10]. Digital customer journeys require not only the artificial intelligence (AI) - enabled automation of decisions traditionally made by claims handlers but also IT architecture that supports real-time digital interactions with customers. Technology should be seen as the fuel for the organization's strategy.

According to the Insurance Governance Leadership Network [5], digital transformation is not just related to the emergence of new technologies. Digitalization provokes a lot of changes in the operation of insurance companies, across the entire value chain, from underwriting and risk management to claims.

New digital technologies contribute to the improvement of insurers' capabilities to encourage insurers to interact more with them. This consumer centric approach gives insurers an opportunity to learn more about consumers' preferences and the risks they want to insure or they have already insured.

In today's business environment, faced with numerous risks, risk managers have to make different decisions, including decisions on retention or transfer of risk, techniques of risk retention or transfer, type of insurance coverage, investment in projects that should reduce frequency and size of damages as well as economic justification of such projects, etc. All decisions are based on cost/benefit analysis and taking into account a lot of factors that influence the risks in order to improve financial performances. Making those decisions requires the application of modern information technologies. In numerous calculations of parameters that enable risk management, such as probability, standard deviation, value at risk (VaR), present value and time value of money, net present value, risk adjusted return on equity and others, depending on the type of risk and specific situations, various tools supported by information technology solutions are implemented, which include risk management information systems, intranets and risk management websites and risk maps [11].

A growing number of projects incorporate "Smart Earth" technologies ICT, remote sensing, big data and social media, in order to design more dynamic, responsive and accountable risk management. Thanks to the implementation of sensing capacities, data available, and big data analysis digital technologies facilitate prediction, understanding, visualizing disasters, and claim management, as well as recovery in the aftermath [12].

\subsection{Use of Information Technologies in Sales and Distribution}

Initially, the presence of insurance companies on the Internet was based on their web presentations [13]. Starting in the late 1990s, insurance companies in Europe started online sells of life insurance. It is also possible to use social networks as an important component of digital marketing. Social media is becoming an integral part of marketing, thereby creating risks to brand value and reputation [6]. Insurers use social networks to share their positive and negative experiences with insurance companies in terms of FNOL, claims, personal data mishandling, etc. [10]. Insurance companies should also consider implementation of a new marketing model, characterized by technological development and integrated marketing communication [14]. Because insurance customers are focused on digital modes of interaction, insurers focus on digital go-tomarket techniques in order to attract them. Insurers should digitally reengineer their own internal operating models and embrace new technologies in order to attract and retain new digital consumers [15].

Internet enables access to more potential insureds and availability of insurance service customized to the consumer's needs, multimedia and interactivity, which is 
particularly important for developing relationships with current and potential insureds. Mitrovic-Veljkovic et al. (2019) emphasized that implementation of digitalization in a business model requires facing a major shift in the entire digital environment [16]. The most important benefit of using the internet is the significantly lower cost in comparison to other distribution channels [6]. The digitalization of online sales and distribution enables insurers to offer a multi-channel presence and customized experience to clients. Digitizing the claims process involves redesigning the process flow from the customer's perspective and applying technology to facilitate each step in the back-end of the customer journey. Insurers can be more responsive to customer requests, automate low-value transactions, and expedite the claims process [10].

For the property and casualty $(\mathrm{P} \& \mathrm{C})$ industry, digitalizing the claims function generates huge potential reflected in improving three KPIs that add value - customer experience, efficiency, and effectiveness [10].

The key disadvantage of selling insurance services online is the insecurity inherent in doing business online, and especially in providing insurance coverage as a "promise of future payment" [13].

\subsection{Insurtech}

The Insurtech trend is part of a broader trend in the application of information and communication technologies in financial services known as FinTech, which originated in the first decade of the $21^{\text {st }}$ century. The Insurtech covers a variety of concepts, from the broad concept of digitalization and the application of information technology in the business of insurance companies to the designation of new competition for insurance companies that originate from the technology sector and are entering the insurance business. The Insurtech includes technologies such as artificial intelligence (AI), chatbots and advanced predictive analytics. Key innovations under the term Insurtech are big data and predictive analytics, Blockchain, Internet of things (IoT), telematics, drones and satellites. Insurers with totally digital business models, such as Lemonade in the United States, Youse in Latin America or Nexible in Europe are using digital applications such as chatbots. This results in simplifying processes and activities across the entire value chain, resulting in improving customers' satisfaction and experience as well as adding value [10].

Competitors might emerge outside the insurance industry, mostly from the financial market and banks, but recently competition has been emerging from technology giants and Internet insurance companies. Some global technology companies have a very large market share in their specific market segment, which provides them with unique access to customers and their data. Such companies could enjoy tech-enabled dominant positions and extend their market power to the insurance sector. Besides opportunities for mutually beneficial partnerships with insurers, they could also become direct competitors, putting pressure on profit margins and challenging the insurers, especially at their interface with customers. Over the past few years, global investment in Insurtechs has grown from \$250 million in 2011 to \$2.3 billion in 2017 . Although Insurtechs mostly emerged in the United States, only $38 \%$ of all Insurtechs are currently headquartered there. According to the latest figures, there are more than 1500 Insurtechs globally and $37 \%$ are based in Europe, the Middle East, and Africa (EMEA), predominantly in Germany and the United Kingdom. An analysis from McKinsey's Panorama Insurtech database shows that around $39 \%$ of Insurtechs are focused on the commercial segment, mostly in SMEs [17].

Certain Insurtech segments such as sales via mobile phones, the use of social networks or interactive sites, big data, AI, IoT and cloud computing may also be applied by traditional insurance companies, but Insurtech is an opportunity for new competitors. Most Insurtechs are not currently seeking to completely transform commercial lines but are more focused on enabling or extending the insurance value chain. In personal insurance, Insurtechs played the role of digital attackers and captured market share at specific points in the value chain. Lacking the scale and expertise needed to excel in commercial, Insurtechs are viewed by executives not as competitors to be feared but as potential partners that could accelerate their digitization efforts [17].

A typical example of Insurtech is Amazon.com. This company is a world leader in product sales and more recently online services. This company employs around 400000 workers worldwide. Amazon provides warranty service for merchandise sold and is also planning to provide insurance coverage. Google also sought to develop a motor insurance through Google Compare but failed primarily due to their misunderstanding of the specifics of insurance.

Some of Insurtech companies are Brolly, Cover, Sosure, ZhongAn and others. Apart from the developed US and UK markets, some of these companies emerged in China. In 2016, there were 173 newly launched Insurtech companies in China. ZhongAn is the first such company in the Chinese market and in 2017 it provided an additional capital of $\$ 1.5$ billion for development, thus becoming the largest Insurtech company in the world. ZhongAn has underwritten 630 million insurance policies and has more than 150 million clients.

Insurtech is attracting increasing attention, as shown by Google Trends data for the period 2004 to the present (see Fig. 1).

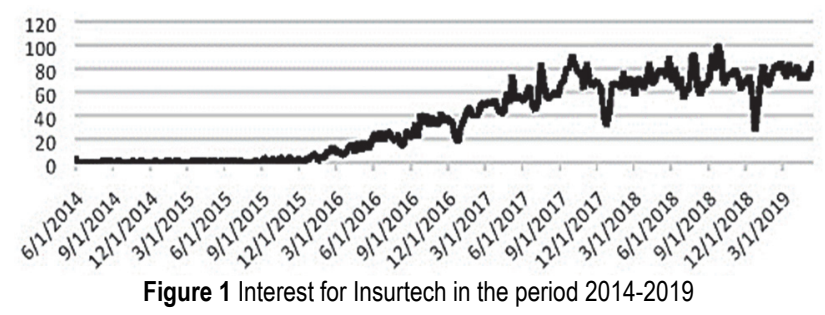

Insurtech has attracted huge investments not only from insurers, reinsurers and technology companies but also from other investors in the capital market. Fig. 2 shows investments in digitalization of insurance and reinsurance, i.e. Insurtech.

It can be seen in Fig. 2 that Insurtech investment is growing significantly. Over the period under review, more than $\$ 8.5$ billion was invested in the development of 599 Insurtech joint ventures. Fig. 3 shows the geographical 
distribution of individual transactions, i.e. investments in Insurtech.
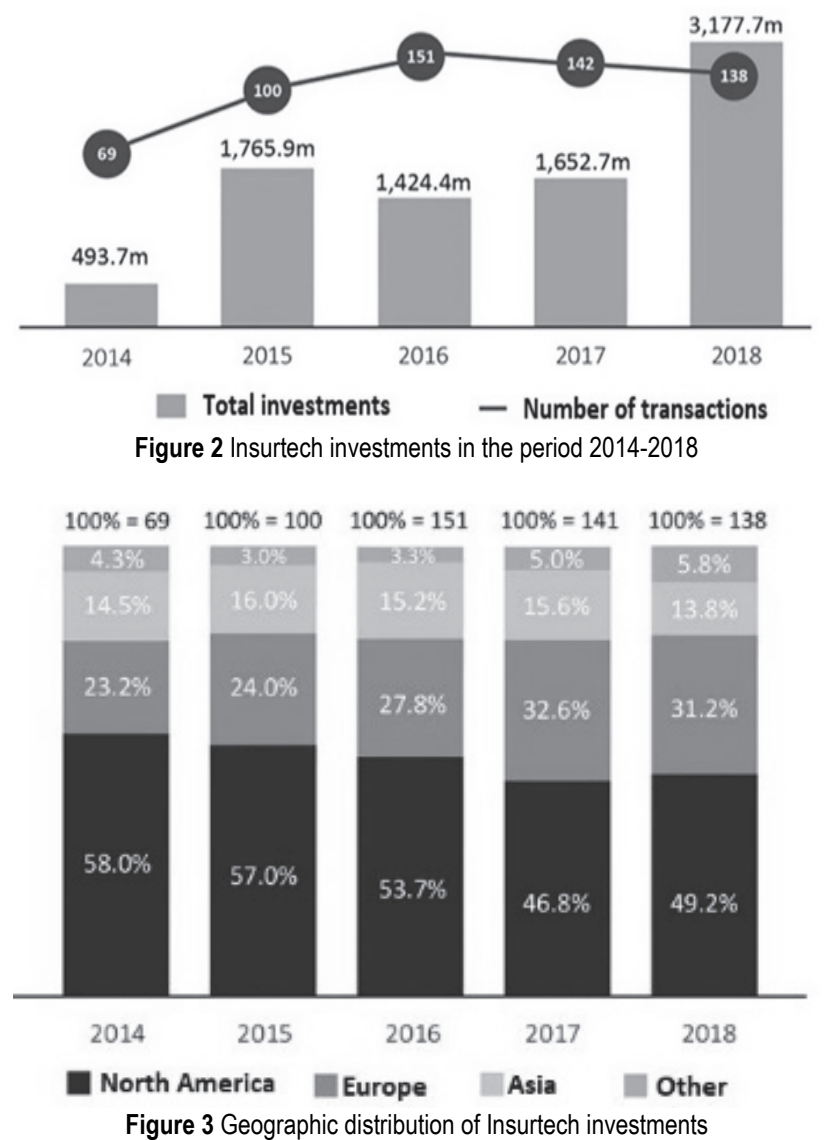

As Fig. 3 shows, the largest investments in Insurtech are present in North America, but the trend of increasing this type of investment is also characteristic for Europe in the observed period. The emergence and development of Insurtech are of particular importance for the development of the insurance market, through offering new insurance services such as pay as you use insurance; also, the emergence of exclusively online insurance companies, especially in China. An increasing number of Insurtech companies that challenge traditional insurance companies to improve their services and gain competitive advantage in comparison to easily available and price efficient insurance services can be expected.

\subsection{Big Data and Predictive Analytics}

Insurance companies have always been big users of data in analysing and measuring the risks they take into insurance coverage, setting conditions for insurance policies and assessing the risk (accepted by insureds) as well as conditions for insurance contracts and claims. Insurers have strong analytic capabilities compared to their peers in other industries. Having in mind that analytics has been a core component of the traditional insurance business model, insurers in new digital ecosystems can provide analytics-as-a-service to other industry players [18].

Digital technologies enable better assessment of risks and insurance premiums based on Big data processing. Data available to insurers is expanding exponentially from a broad range of sources not only from traditional data providers, but also public entities and enterprises generating data "exhaust" from business activities. This enables proper determination of premiums, risks, and claims. Big data, predictive analytics, and IoT, which enabled the connectivity of portable and telematics devices, were particularly significant. In summary the impact of digitalization on insurance development is shown in Tab. 1.

Table 1 The impact of digitalisation on the value chain of insurance companies [19]

\begin{tabular}{|c|c|}
\hline \multirow{2}{*}{$\begin{array}{c}\text { Product } \\
\text { development }\end{array}$} & $\begin{array}{l}\text { Big Data facilitates the collection of new behavioral } \\
\text { data, allowing for personalization }\end{array}$ \\
\hline & $\begin{array}{l}\text { Telematics devices allow a reduction of related risks } \\
\text { but create new risks, such as cyber risks }\end{array}$ \\
\hline \multirow[t]{2}{*}{$\begin{array}{c}\text { Sale and } \\
\text { Distribution }\end{array}$} & $\begin{array}{l}\text { The platforms contain numerous offerings and enable } \\
\text { comprehensive comparison and choice for potential } \\
\text { insureds }\end{array}$ \\
\hline & Insurtech start-ups enter the insurance market \\
\hline \multirow{2}{*}{ Actuarial } & $\begin{array}{c}\text { Instant information and Big Data enable predictive and } \\
\text { evaluative analytics }\end{array}$ \\
\hline & $\begin{array}{c}\text { More detailed segmentation is possible thanks to the } \\
\text { large processing power }\end{array}$ \\
\hline \multirow[t]{2}{*}{ Claims } & $\begin{array}{l}\text { Telematics devices enable more accurate damage } \\
\text { assessment and fraud reduction }\end{array}$ \\
\hline & Technology reduces claims processing time \\
\hline
\end{tabular}

Digital technologies can increase revenues by up to $28 \%$ over a five-year period, reduce claims costs by up to $19 \%$, and reduce administration costs by up to $72 \%$ [20].

Predictive analytics is evolving particularly based on the potential of digital technology and a big data. These groups of data are so large or complex that traditional processing with application software is not enough. The company that can predict earthquakes on the base of big data, "Terra Seismic", has been nominated for the Nobel Peace Prize. With predictive analytics, this firm would be able to predict an earthquake before it happens so that the population can be evacuated in order to protect them.

Claims and costs of their processing represent the largest cost item, typically about $75 \%$ of insurers' total costs, which strongly reflects on the financial performance of the insurance company. An Accenture research study from 2001 identified that claims processing costs can be significantly reduced by about $15 \%$ without affecting good business practices and providing high quality services to insureds and found that more than $40 \%$ of the time spent on claims management goes into routine operations. Digital technology can ensure faster and more accurate claims management by providing improved service to insureds at the same time.

A particularly important role of big data and predictive analytics is to prevent insurance fraud. Where people fail, big data and predictive analytics can identify gap between insureds, third parties involved in a claim and even social media and online activities of insureds. Fraudulent claims that cost the worldwide insurance industry an additional $10 \%$ of total claims can be identified easily and quickly.

Using Big data enhances the insureds' experience as well as satisfaction. Insurers should develop a new digital operating model in order to add value to the customers experience by using artificial intelligence and digital technologies in the processes of digital claims prevention, digital first notification of loss (FNOL), automated claims management, digital loss assessment and repair, automated settlement [10]. Lemonade has worked to redefine the 
customer experience with an innovative, chatbot-based FNOL system that creates automated claims pay-outs within seconds.

Big data analytics enables insurance sellers, agents and brokers to identify inconsistencies in insurance policies and to make more relevant proposals. Through the use of big data and predictive analytics, it is possible to fully understand insureds, their behaviour, and their needs and expectations, which is crucial for improving relationships with them. This will allow insurers to add value to their services. A digital ecosystem is an interconnected set of services that allows users to fulfil a variety of needs in one integrated experience.

Modern technologies enable better assessment of the individual risks specific to individual insureds, which is in the interest of both insurance companies and the insureds. If customers let insurers track their habits via wearable monitoring devices, insurers can use the data to influence behaviour and reduce risks. The flipside of insurers gaining more data about their customers is a rising risk of antiselection in life and health insurance. The use of big data in risk assessment of individual insureds allows insurance companies not only to adequately determine the insurance premium, but also to modify consumer behaviour in some way. The new possibilities introduced by big data analytics and other digital technologies could enable insurers to offer individual risk-based insurance. Based on available data on the behaviour of the insureds while driving or in relation to their health, insurance companies' representatives may persuade insureds to change their habits to drive safer, live healthier, and achieve lower insurance premiums. An increase in the amount of information and knowledge available to society could lead to a decrease in the frequency of some risks, such as vehicle accidents, and may even cause some risks to disappear altogether if they become totally predictable. On the other hand, other newly emerging risks, such as cyber, will increase.

The Boston Consulting Group and Morgan Stanley Bank estimated that, if all available damage prevention techniques were applied, damage to insured households would be reduced by $40 \%$ to $60 \%$. Also, detailed monitoring of the insureds' behaviour can provide insurance companies with sufficient data available to prevent the occurrence of negative risk selection, moral hazard and in particular the occurrence of fraud by the insured.

Big data and predictive analytics provide numerous benefits to insurance companies as well as insureds by reducing costs, enhancing insureds' experience, improving sales productivity, improving risk acceptance into insurance coverage and improving claims management.

\subsection{Internet of Things (IOT), Telematics Devices, Drones and Satellites}

Internet of Things (IoT) refers to the connectivity of billions of physical devices worldwide equipped with sensors and software, currently connected to the Internet to collect and share data. Thanks to the IoT many devices use the necessary data at the right time, enabling their regular functions. According to a recent survey by Insurance Nexus, by 2025, there will be up to over one trillion connected devices. More than 300 senior insurance executives participated in the survey and only $24 \%$ responders said they felt they were ready.

The IoT provides numerous opportunities for insurance companies. The emergence of smart homes that imply the connectivity of all devices to the Internet provides insurers with a unique ability to adapt and apply risk management techniques more effectively. For example, intelligent sensors can monitor the flow of water through pipes to prevent damage that may be caused by leaks from water pipes.

The IoT allows a better assessment of risks making insurance more efficient for both insurance companies and insureds [21]. By knowing more about the risk, insurance companies can reduce negative effects of damages and offer some clients a lower insurance premium that corresponds to a lower risk. The IoT enhances insurer's performances by reducing costs, enhancing consumer experience and enhancing the effectiveness of risk acceptance into insurance coverage.

The industry has already seen a number of high-profile partnerships between established insurers and tech companies. The analytics start-up Progressive partnered with Zubie, a vehicle-tracking and engine-diagnostic device, to give customers insight into how their driving habits affect their insurance premiums. Manulife is collaborating with Indico Data Solutions to develop a deep learning tool that analyses unstructured financial data [18]. Insureds may therefore not want to share the same or additional information with insurance companies. Insurers may also object to data collection and management challenges related to the IoT and other connected devices.

A particularly significant role of information systems is reflected in accepting risks in insurance coverage. In the area of risk identification and assessment, examples include geographic information systems that began to develop after Hurricane Katrina as well as the use of satellite, GPS devices in vehicle insurance. Also important are tracking devices, credit card usage histories and social media, especially Facebook and Twitter, which allow insurance companies to obtain big data relevant to the risk assessment of individual insureds.

Sensors and telematics devices would not function properly without the IoT and through different applications have the potential for use in various types of insurance:

1) information about driver behaviour in real-time for motor vehicle insurance,

2) smart applications, including thermostats and security alarms for household insurance;

3) fitness tracking devices for life and health insurance;

4) warehouse monitors and fleet or truck fleet management in case of commercial insurance.

The data these devices provide is precious for more accurately accepting risk in insurance coverage, faster management of claims and product innovation. Telematics devices provide the basis for Pay as you drive or Pay as you live insurance that rewards healthy behaviour and follows the life of the insured. 21st Century Insurance was the first to implement GPS technology in order to enable parents to determine the exact car location and the driving characteristics of their teenage children. Also, with the Pay as You Drive model Siemens has enabled insurance companies to offer insurance premiums that reflect individual driving characteristics of their clients and to 
resolve claims in a more reliable way. Insurance coverage for mileage is attractive to those insureds who drive relatively low mileage per year. There is also other information that is collected from the insured in order to better assess the risk accepted in the insurance coverage. In addition to Pay as You Drive, there are other devices that track the insured's driving behaviour, such as sudden braking, driving breaks or stopping driving at night.

Regarding claims management if the insured has had a traffic accident, photographs sent to the insurer will be accepted as valid proof for claim compensation and the software built into the car will be able to send an estimated amount of damage, which will greatly speed up the payment of damages, but also eliminate the possibility of insurance fraud. By using machine learning, automated counsellors will be able to perform virtual accident reconstruction. They will also make virtual contact with the insureds and inform them when the damage will be compensated. Everything will be realized in real time or approximately to real time.

Insurance companies providing health insurance services are making efforts to develop similar devices or ways to obtain useful information from already existing devices that monitor behaviour of insureds, which is known as the Pay as You Live model. If insureds use devices such as smart watches and the like that monitor their movement, exercise, or physical activity, better insurance conditions might be offered to them. Some health insurers give their insureds a certain amount of money to accomplish a specific goal (e.g. 10000 steps a day). Further development of monitoring devices could be expected in order to allow insurers to obtain even more detailed individual risk assessment data, such as sensors that could signal pipe weakness before water leaks, or the existence of an indicator of blood sugar levels in contact lenses, which would indicate the quality of insured's diet. Ping An, a Chinese insurer with more than one million employees and agents, has included healthcare consultations, auto sales, real estate listings, and banking services into the offer. Now more than 350 million online customers can use different services through a single customer portal called the One Account. This generates added value for the customers and results in the world's most valuable insurance brand. Ping a Good Doctor has more than 77 million registered users and more than 250000 users need consultations every day [18].

The obvious advantage is that the insurance premiums may be based on the actual use and habits of the insured. Also, the process of managing claims is automated. For example, in the case of motor vehicle insurance, telematics devices register a car accident and automatically submit the first notification of loss (FNOL). Information on the damage and the claim for compensation is supported by a textual interaction between the driver and the insurer. The resolution of the claim can be offered to the insured in 60 minutes or less.

Drones and satellite technologies are being increasingly used in order to improve the risk acceptance in the insurance coverage, as well as in claims management. In agriculture drones are also useful in the assessment of risks. In household insurance, satellites can provide information on the condition of roofs, chimneys, and surrounding terrain so insurers can determine households they want to accept into insurance coverage and can calculate competitive and profitable insurance premiums. Data from drones and satellites connected to communication devices can initiate the process of sending notice to insureds regarding new premium options or adjustments in existing insurance contracts.

In terms of claims management, drones and satellites can perform a number of tasks instead of employees in insurance companies. Remote sensing damage assessment can significantly reduce the processing time of claims. This is especially useful in situations such as floods, fires and natural disasters, where direct assessment is impossible. It is estimated that drones and satellites can contribute up to $40 \%$ in improving risk acceptance into insurance coverage and in resolving claims.

\subsection{Blockchain Technology in Insurance}

Blockchain is a list of records, called blocks that are interconnected by using cryptography. It is a public decentralized database where transactions are executed and verified anonymously [22]. The Blockchain has no transaction costs, but there are infrastructure costs that are necessary for the implementation of this technology [23]. One party in the transaction initiates the process by creating a block that is verified to be added to the chain, stored across the internet, thus creating a unique record with a unique history. Counterfeiting individual records would mean counterfeiting the entire chain in millions of instances, which is impracticable. Trust in a third party appears to be a much wider concept than the trust a blockchain can offer. This technology appears to provide trust in integrity of the data recorded on the blockchain, but the trust needed by a participant goes beyond integrity of data alone [24].

The internet of things and blockchain are disruptive technologies that have received a huge attention from industry, academic and financial technologies [25].The Blockchain technology has the potential to revolutionize finance as a whole, especially the capital and stock markets, banking and insurance through the elimination of bank accounts and all services offered by banks. This technology has a lot of possibilities for application in insurance through the protection of information, reduction of administrative costs, and consequently, reduction of transaction costs. Although money and information can also be secured through Blockchain technology, insurance will continue to exist because security requires trust, which is mostly related to the institution and Blockchain technology cannot be a substitution for the insurance institution.

Blockchain creates the basis for totally new business models such as mutual insurance, thanks to virtual assistance in determining premiums, managing claims and other tasks. Also, Blockchain provides a new level of transparency of information and precision with easier access to all parties in the insurance contract. With higher levels of autonomy, features of the Blockchain architecture provide a strong digital foundation for faster and more secure transactions, enhanced transparency and reduced risk.

According to Pavlovic [22] the greatest potential for developing the application of Blockchain technology in 
insurance lies in: microinsurance, claim payment, antifraud, reinsurance, smart contracts, undertaking of standard and specific risks.

\subsection{Negative effects of Implementing Digital Technologies into the Insurance Sector}

In addition to the numerous opportunities related to implementing digital technologies in insurance business, which include cost savings based on reduction of claims and administration costs, higher efficiency and competitiveness, improved reaction to the requirements of insureds, government and rating agencies, lower insurance premiums and better risk and capital management, digitalization induces some threats, too. The negative aspects of digitalization are reflected in the increase in costs due to the necessary investment in employees' education, as well as hardware and software that will support the digitalization, at greater risk of a digitalizationbased business model being copied, and the emergence of new Insurtech competitors, greater risk exposure, primarily cyber risk, the resistance of certain segments of the insureds, especially the elderly, as well as the need for developing customer relationship management (CRM) because of the lack of personal contact to insureds in sales based on information technologies. The lack of consumers' information and experience leads to information asymmetry and generates financial consequences for consumers which finally could disturb stability of financial market if consumers lose their confidence in the financial market [26]. Melovic et al. (2020) researched the problem of electronic CRM in SEE companies and found that although competition pressure and customer expectations can trigger companies to make the decision to adopt eCRM, management of a company must differentiate themselves from external influences in order to avoid the trap of copying the behaviour and models of other companies [27].

There is increasing exposure to the risk of financial loss, disruption, reputational risk due to problems in the operation of information and telecommunication systems, as well as misuse of data protection and privacy regulations, regardless of the cause of risk. According to Schmidt [1] it is essential for insurers to use personal data of insureds responsibly, to preserve their trust, and at the same time, enable compliance with data protection requirements, always keeping in mind ethical issues. Research of Bostan and Akman [28] indicates the relationship between education level, web security awareness, and knowledge about different secure web applications. There are ethical and societal concerns, for example in the areas of privacy and data protection, or regarding the evolving access to insurance for high-risk individuals. According to the Deloitte [6] study customer profiling is prominent for better customer experience, but the profiling process should be aligned to protect the privacy of customer data.

In 2002, the International Association of Insurance Supervisors identified the risks of implementing new technologies into the business of insurance companies and divided them into 6 groups: strategic risks, operational risks, transaction risks, data security risks, connectivity risks, and business risks.
The Council of Europe Cybercrime Convention [29] signed in Budapest in 2001, also points to the importance of cyber risk, marking criminal activity as illegal access, illegal interruption, data interference, system interference, device abuse, computer related forgery, fraud, child pornography and infringements of intellectual property rights.

The need for sensitive data protection is attracting more attention than ever before, thanks to the adoption of the General Data Protection Regulation (GDPR). Insurance companies are particularly at risk because of the availability of highly sensitive customer information. Available data is essential for insurance companies. Without adequate, relevant, timely and complete information, it would be almost impossible for insurance companies to provide insurance services on a sustainable basis. Insurance companies have to provide data protection to ensure business continuity, avoid risks, regulatory sanctions but most importantly to retain the trust of the insureds. The trend is that customers will have to allow insurers to use their data. Vatamanescu et al. [30] investigated the relationship between consumer protection awareness of online buyers and their behaviour by online purchasing decision-making. The results of their research showed statistical significance between awareness of consumer protection and consumer behaviour, which means if consumers are aware of protection they are open and they buy products online due to the variety of offers, to the possibility of comparing offers, to the acknowledgement of other customers' experiences and reviews and to the fact that online suppliers are more controlled by the authorities in the field of consumer protection. Having in mind that trust is the cornerstone in the relationship between insurers and insureds and that, due to digitalization and new technologies, even more insurance product can be purchased online, awareness of online protection of current and potential insureds could considerably impact their decision to purchase insurance coverage via Internet. This is particularly important for Millennials and generation $\mathrm{Z}$. Changes towards digitalisation in the work of insurers require greater investment as well as highly integrated platforms such as agency portals, online as well as the use of mobile devices, completing policies and filing compensation claims. The results of the research of Lyskawa et al. [31] showed that there is a different tendency in the raising of ICT investments and the values of gross premiums, claims, and expenses. The biggest insurance group in the European Union started spending more money on software and IT comparing 2017 to 2008 . It could be seen that insurance companies become more interested in new technologies and programs. Although investments in digitalization provide new strategic benefits, they cause insurers greater exposure to cyber risk. Cyber-attacks on insurance companies are growing exponentially with the efforts of insurers to introduce digital channels in order to enhance relationships with insureds, offer new insurance services and expand the share of their clients' financial portfolios [9].

Ernst \& Young [32] explored how insurance companies manage cyber risk exposure based on a sample of 1,755 insurance executives. As many as $55 \%$ of insurers outsource estimation of cyber risk exposure. When asked 
about the focus of the security function of the information system, $11 \%$ of insurers indicated that this function focused on devices connected to the IoT, 7\% focused on advanced machine learning or artificial intelligence, 5\% focused on robotic processes, and $4 \%$ on Blockchain and crypto currencies. About $49 \%$ of responders found significant cyber-attacks on their organization, as many as $71 \%$ of responders did not think it was very likely that their organization could detect a sophisticated attack, 59\% thought that there was no adequate management support, $83 \%$ indicated that identification of cyber risks in an attack on an organization is likely to contribute to an increase in the information security budget, $19 \%$ of insurers did not know the financial impact of cyber-attacks on their key customers, $11 \%$ of responders believed that their level of exposure to cyber-attack is fully sufficient, $56 \%$ saw criminal unions as the most likely source of cyber-attacks, while $82 \%$ believed that the most common cause of cyberattacks is employee negligence.

Cyber risks are not understood well enough and are evolving rapidly. Insurers need to improve their understanding and awareness of the types and dangers of cyber risk. Also, insurers must play an active role in the prevention of cyber risk, both in their exposure to this risk and their clients' exposure to it [33].

According to Elingand Lehmann [2], some questions still have to be answered regarding the regulation of Insurtechs, the priorities of digitalization in terms of customer, products or processes, the justification of investments in new technology and digitalization, but ethical issues too.

The results of research of Petzold et al. [34] pointed out that the innovation's disruptive characteristics in the beginning do not necessarily lead to a disruptive effect but that it is the dynamics "in between", shaped by the entrant, the incumbent and other actors, that decide the innovation's final effect on the mainstream. The degree of disruptiveness depends on the development of disruptive technologies and their integration within business models. Digital Transformation across industries has led to a rapidly changing business environment which offers exponentially growing opportunities for new capabilities and initiatives. Despite all the challenges, threats and risks that the evolving environment presents, organizations cannot overlook the opportunities that "moving to digital" brings forth along with the profound impact that it shall have on them [6].

\section{CONCLUSIONS}

Digitalization is one of the issues the insurance industry is facing. In addition to the positive effects of embracing new digital technologies in the business of insurance companies, some risks and threats related to the digitalization process have emerged. Some of them are the increasing risk of copying a digitalization-based business model and the emergence of new attackers - Insurtechs, increasing exposure to cyber risk, the possibility of making wrong decisions based solely on digital data processing, additional investments in the highly integrated platforms such as agency portals and education of employees, and problems in relation to insureds due to the lack of personal contact in sales based on information technologies.
Regardless of the risks and threats related to digitalization processes in the operation of insurance companies, they offer unlimited opportunities to develop and enable new services to insureds through customer-centric business orientation and through establishing partnerships with IT companies. Embracing of new digital technologies enables numerous advantages and contributes to creation of added value for insurance companies and their clients, regardless of risk and threats that emerge in digitalization processes. This research is among the first comprehensive studies of the digitalization processes in insurance. It is of great importance to insurance companies which are on their track to implement new digital technologies in their strategic business orientation. Its main weaknesses are related to the fact that some of the digitalization trends have not yet been applied by insurance companies, such as Blockchain, while others are relatively novel, so there is no available data about their full effects, but we expect that in the next five to ten years they will be fully embraced. Finally, our further research will focus on the wider analysis of application of digital technologies in insurance industry in terms of comparison of performances indicators of insurers that have already embraced the digital technologies.

\section{REFERENCES}

[1] Schmidt, C. (2018). Insurance in the Digital Age - A view on key implications for the economy and society. The Geneva Association. Retrieved from https://www.genevaassociation.org/researchtopics/digitaliza tion/insurance-digital-age

[2] Eling, M. \& Lehmann, M. (2017). The Impact of Digitalization on the Insurance Value Chain and the Insurability of Risks. St. Gallen: Institute of Insurance Economics. https://doi.org/10.1057/s41288-017-0073-0

[3] Newman, D. (2019). Every Digital Transformation Needs Risk Management. Retrieved from

https://www.forbes.com/sites/danielnewman/2019/07/09/ev ery-digital-transformation-needs-riskmanagement/\#7ff29fa27141

[4] See https://www.floridatechonline.com/blog/informationtechnology/disruptive-technology-definition-and-examples/

[5] Insurance Governance Leadership Network (2015). Risk and opportunity in an increasingly digital world. Retrieved from

https://www.ey.com/Publication/vwLUAssets/EY_Risk_a nd_opportunity_in_a_digital_world/\$FILE/ey-risk-and opportunity-in-an-increasingly-digital-world.pdf

[6] Deloitte Touche Tohmatsu India LLP (2018). Managing Risk in Digital Transformation.

[7] Njegomir, V. \& Ćirić, J. (2011). Information technology for risk management support. Annals of Faculty Engineering Hunedoara - International Journal of Engineering, 9(1), 109-114.

[8] Marshal, A. \& Weiss, J. (2008). Malicious Control System Cyber Security Attack Case Study. Maroochy Water Services, Australia. Retrieved from

https://www.mitre.org/publications/technicalpapers/malicio us-control-system-cyber-security-attack-case-study maroochy-water-services-australia

[9] Mc Kinsey, (2017). Digital disruption in insurance: Cutting through the noise. Retrieved from https://www.mckinsey.com/ /media/mckinsey/industries/fi nancial $\% 20$ services/our\%20insights/time $\% 20$ for $\% 20$ insura nce $\% 20$ companies $\% 20$ to\%20face $\% 20$ digital $\% 20$ reality $/$ dig ital-disruption-in-insurance.ashx 
[10] Brüggemann, P., Catlin, T., Chinczewski, J., Lorenz, J. T., \& Prymaka, S. (2018). Claims in the digital age: How insurers can get started. Digital Insurance in 2018, McKinsey and Company, 3-17. Retrieved from

https://www.mckinsey.com/ /media/McKinsey/Industries/F inancial\%20Services/Our\%20Insights/Digital\%20insurance $\% 20$ in $\% 202018 \% 20$ Driving\%20real\%20impact\%20with\% 20digital\%20and\%20analytics/Digital-insurance-in2018.ashx

[11] Rejda, G. E. (2005). Principles of Risk Management and Insurance. Pearson Education, Inc.

[12] Bettini, G., Gioli, G., \& Felli, R. (2020). Clouded skies: How digital technologies could reshape "Loss and Damage" from climate change. WIREs Clim Change, 650, 1-22. https://doi.org/10.1002/wcc.650

[13] Njegomir, V. (2011). Osiguranje. Novi Sad: Ortomedics Book.

[14] Bešić, S. (2019). The Application of Contemporary Marketing Concept in the Sense of the Improvement of Business Subject Competitiveness. Technical Gazette, 26(2), 441-448. https://doi.org/10.17559/TV-20181114195448

[15] Boston Consulting Group (BCG). Retrieved from https://www.bcg.com/industries/insurance/digital.aspx

[16] Mitrovic-Veljković, S., Raut, J., Melović, B., \& Ćelić, Đ. (2019, July). Development of Digital Entrepreneurship and New Business Models as a Result of the Expansion of Information Systems. International Joint conference on Industrial Engineering and Operations Management, 396404. https://doi.org/10.1007/978-3-030-43616-2_42

[17] Chester, A., Hoffman, N., Johansson, S., \& Olesen, P. B. (2018). Commercial lines Insurtech: A pathway to digital. Digital insurance, 55-63.

[18] Catlin, T., Lorenz, J. T., Nandan, J., Sharma, S., \& Waschto, A. (2018). Insurance beyond digital: The rise of ecosystems and platforms. Digital insurance, 21-32.

[19] Cappielo, A. (2018). Technology and the insurance industry. reconfiguring the competitive landscape. Pisa, Italy. https://doi.org/10.1007/978-3-319-74712-5_2

[20] Naujoks, H., Mueller, F., \& Kotalakidis, N. (2017). Digitalization in Insurance: The Multibillion Dollar Opportunity. Bain \& Company. Retrieved from https://www.bain.com/insights/digitalization-in-insurance

[21] Mašić, N. (2014). Internet stvari - nova digitalna pomoć osigurateljima. Svijet osiguranja, Zagreb:Tectus.

[22] Pavlović, B. (2018). Potencijal veći od rudarenja Bitcoina. Svijet osiguranja, Zagreb:Tectus.

[23] Rosic, A. (2017). What is Blockchain Technology? A Stepby-Step Guide for Beginners. Blockgeeks. Retrieved from https://blockgeeks.com/guides/what-is-blockchaintechnology/

[24] Koens, T., Aubel, P. V., \& Poli, E. (2020). Blockchain adoption drivers: The rationality of irrational choices. Concurrency and Computation: Practice and Experience, 5843. https://doi.org/10.1002/cpe.5843

[25] Shrestha, R. \& Kim, S. (2019). Integration of IoT with blockchain and homomorphic encryption: Challenging issues and opportunities. Advances in Computers, 115, 293331. https://doi.org/10.1016/bs.adcom.2019.06.002

[26] Armeanu, D., Istudor, N., Florinel, S. M., \& Burca, A. M. (2014). Analysis of the Romania insurance market based on ensuring and exercising conusmers' right to claim. Amfiteatru Economic, 16(36), 550-562.

[27] Melovic, B., Rondovic, B., Mitrovic-Veljkovic, S., BaticOcovaj, S., \& Dabic, M. (2020). Electronic customer relationship management assimilation in Southeastern European companies - cluster analysis. IEEE Transactions on Engineering Management. https://doi.org/10.1109/tem.2020.2972532
[28] Bostan, A. \& Akman, I. (2015). Impact of Education on Security Practices in ICT. Technical Gazette, 22(1), 161168. https://doi.org/10.17559/TV-20140403122930

[29] Vătămănescu, E. M., Nistoreanu, B. G., \& Mitan, A. (2017). Competition and Consumer Behavior in the Context of the Digital Economy. Amfiteatru Economic, 19(45), 354-366.

[30] Convention on Cybercrime - Council of Europe Retrieved from https://www.coe.int/en/web/conventions/full-list//conventions/treaty/185

[31] Lyskawa, K., Kedra, A., Klapkiv, L., \& Klapkiv, J. (2019). Digitalization in insurance companies International Scientific Conference. Contemporary Issues in Business, Management and Economics Engineering 2019. https://doi.org/10.3846/cibmee.2019.086

[32] Ernst \& Young (2017). Cyber strategy for insurers: Managing physical and digital assets to protect brand and reputation.

[33] Deloitte, Global Cyber Executive Briefing, Insurance. Retrieved from https://www2.deloitte.com/be/en/pages/risk/ articles/insurance.html

[34] Petzold, N., Landinez, L., \& Baaken, T. (2019). Disruptive innovation from a process view: A systematic literature review. Creat Innov Manag., 28,157-174. https://doi.org/10.1111/caim.12313

\section{Contact information:}

Vladimir NJEGOMIR, PhD, Full Professor

Union university, Faculty of Law and Business Studies,

Bulevar oslobodjenja 76, Novi Sad, Serbia

E-mail: vladimir.njegomir@flv.edu.rs

Jelena DEMKO-RIHTER, PhD, Associate Professor (Corresponding author)

University of Novi Sad, Faculty of Technical Sciences,

Department of Industrial Engineering and Management,

Trg Dositeja Obradovica 6, Novi Sad, Serbia

E-mail: jciric@uns.ac.rs

Tamara BOJANIĆ, PhD student

University of Novi Sad, Faculty of Technical Sciences,

Department of Industrial Engineering and Management,

Trg Dositeja Obradovica 6, Novi Sad, Serbia

E-mail: tamarabojanic@uns.ac.rs 